\title{
Fermented wheat aleurone induces enzymes involved in detoxification of carcinogens and in antioxidative defence in human colon cells
}

\author{
Katrin Stein*, Anke Borowicki, Daniel Scharlau and Michael Glei \\ Department of Nutritional Toxicology, Institute for Nutrition, Friedrich-Schiller-University Jena, Dornburger Strasse 24, \\ 07743 Jena, Germany \\ (Received 13 October 2009 - Revised 30 March 2010 - Accepted 13 April 2010 - First published online 28 June 2010)
}

Dietary fibre is fermented by the human gut flora resulting mainly in the formation of SCFA, for example, acetate, propionate and butyrate. SCFA, in particular butyrate, may be important for secondary cancer prevention by inducing apoptosis and inhibiting cell growth of cancer cells, thereby inhibiting the promotion and/or progression of cancer. Furthermore, SCFA could also act on primary cancer prevention by activation of detoxifying and antioxidative enzymes. We investigated the effects of fermented wheat aleurone on the expression of genes involved in stress response and toxicity, activity of drug-metabolising enzymes and anti-genotoxic potential. Aleurone was digested and fermented in vitro to obtain samples that reflect the content of the colon. HT29 cells and colon epithelial stripes were incubated with the resulting fermentation supernatant fractions (fs) and effects on mRNA expression of CAT, GSTP1 and SULT2B1 and enzyme activity of glutathione $S$-transferase (GST) and catalase (CAT) were measured. Fermented aleurone was also used to study the protection against $\mathrm{H}_{2} \mathrm{O}_{2}$-induced DNA damage in HT29 cells. The fs of aleurone significantly induced the mRNA expression of CAT, GSTP1 and SULT2B1 (HT29) and GSTP1 (epithelial stripes), respectively. The enzyme activities of GST (HT29) and CAT (HT29, epithelial stripes) were also unambiguously increased (1.4- to 3.7-fold) by the fs of aleurone. DNA damage induced by $\mathrm{H}_{2} \mathrm{O}_{2}$ was significantly reduced by the fs of aleurone after $48 \mathrm{~h}$, whereupon no difference was observed compared with the faeces control. In conclusion, fermented aleurone is able to act on primary prevention by inducing mRNA expression and the activity of enzymes involved in detoxification of carcinogens and antioxidative defence.

Catalase: Fermented aleurone: Glutathione $S$-transferases: Human colon cells: Sulfotransferases

Dietary fibre is considered to be a key component in the health benefits of fruits, vegetables and whole-grain cereals. Cereal grains contain high amounts of dietary fibre and other physiologically beneficial substances, for example, minerals, vitamins and phenolic acids. In wheat grains, the bran fraction, or more precisely the aleurone layer which forms the outer part of the endosperm, is rich in these substances $^{(1)}$. The consumption of dietary fibre may have protective effects on the colon by elevating faecal volume und enhancing defecation, thereby reducing the exposure of colonocytes to cancer risk factors contained in the faeces. In addition, protection may be also a result of the bacterial fermentation of dietary fibre by the formation of SCFA, namely acetate, propionate and butyrate ${ }^{(2)}$.

Butyrate, in particular, has received much attention as a potential cancer-preventive agent, because of its ability to induce apoptosis and differentiation as well as to inhibit proliferation of transformed cells ${ }^{(3,4)}$. Additionally, butyrate could contribute to risk reduction, for example, by enhancing expression of glutathione $S$-transferases (GST) and other enzymes that are involved in detoxification processes ${ }^{(3)}$. Under physiological conditions, butyrate affects human colon cells not separately but rather in conjunction with other fermentation products, which are formed simultaneously by microbial degradation of dietary fibre. Detailed evidence is limited on how fermentation products from dietary fibre sources such as grains interact with human intestinal cells and how these affect cells in comparison with analogous SCFA concentrations or butyrate alone ${ }^{(5,6)}$.

Cancer chemoprevention is characterised by the use of natural or synthetic substances to prevent the development of invasive cancer ${ }^{(7)}$. One mechanism of chemoprevention could involve protection against genotoxic compounds at the initiation and progression stage of colon carcinogenesis. Agents involved in the so-called primary prevention thus impede cancer-inducing compounds from reaching or reacting with specific target sites, for example, by preventing the formation of ultimate carcinogens or reactive oxygen species $(\mathrm{ROS})^{(8)}$. Experimental evidence supports an important role for ROS in the pathogenesis of cancer in rodents and human subjects ${ }^{(9)}$. ROS such as superoxide $\left(\mathrm{O}_{2}\right), \mathrm{H}_{2} \mathrm{O}_{2}$ and hydroxyl radicals $(\mathrm{OH})$ are highly reactive oxidants that are formed during cell metabolism, signal transduction, or indirectly by various types of toxins. An imbalance between

Abbreviations: CAT, catalase; fs, fermentation supernatant fraction; GST, glutathione $S$-transferase; qPCR, quantitative PCR; RIN, RNA integrity number; ROS, reactive oxygen species; SULT, sulfotransferase.

* Corresponding author: Dr Katrin Stein, fax +49 3641 949672, email stein.katrin@googlemail.com 
the formation of ROS and the antioxidative defence system results in oxidative stress. This can cause damage to lipids, proteins and/or DNA. Therefore, an increase in ROS in the cell contributes to numerous degenerative diseases, including the initiation and promotion/progression stages of carcinogenesis ${ }^{(10-13)}$

For protection against oxidative stress the cells express different types of stress-response enzyme systems, including GST, peroxidases and catalase (CAT). $\mathrm{H}_{2} \mathrm{O}_{2}$ is rapidly detoxified by CAT, which is the key defence system against oxidative stress. Therefore, a high level of expression or activity could be associated with less genetic damage and thereby reduce colorectal cancer risk $^{(12,14-16)}$. Furthermore, GST and sulfotransferases (SULT) are phase II enzymes which can detoxify a number of carcinogens by conjugation of diverse electrophiles with glutathione or a sulfate group, respectively, and thus prevent these metabolites from binding to and damaging $\mathrm{DNA}^{(17)}$. It has been proposed that an enhancement of their activity might result in more efficient elimination of carcinogens and therefore reduce the susceptibility to cancer $(15,18,19)$.

The aim of the present study was to examine whether the expression of genes involved in stress response and toxicity can be modulated by complex fermentation supernatant fractions (fs) of aleurone obtained from different wheat varieties. The fs were generated using an in vitro batch model ${ }^{(20)}$. This model simulates the physiological conditions in the human intestine and provides an experimental approach to investigate the interactions of the resulting fermentation products, for example, SCFA, with the colon cells. Another aim was to investigate the functional consequences of an increased expression of the respective genes. We thus determined the enzyme activities of CAT and GST in HT29 cells incubated with the complex fs. Additionally, we compared the effects of the fs with those of butyrate and with a SCFA mixture prepared according to the fermentation samples. As mentioned above, GST and CAT are connected with inactivation of cancer risk factors, for example, $\mathrm{H}_{2} \mathrm{O}_{2}$. Hence, it was of interest if the complex fs exhibit an increased detoxifying potential towards $\mathrm{H}_{2} \mathrm{O}_{2}$. Furthermore, an important aim of the study was to examine whether genes and enzyme activities involved in detoxification can also be elevated in non-transformed human colon cells. In addition, we compared the effects in both human colon cell types, which were used in the present study. The results of our experiments were expected to enhance our knowledge about processes that are involved in the detoxification of potential genotoxic and carcinogenic agents.

\section{Methods and materials}

\section{Dietary fibre source}

Both varieties (European and American) of wheat aleurone were provided from Kampffmeyer Food Innovation $\mathrm{GmbH}$ (Hamburg, Germany). Preparation of the aleurone fraction (ASP-2 preparation with high purity) was done by Bühler AG (Uzwil, Switzerland) according to Bohm et al. ${ }^{(21)}$. To maintain stability of the aleurone fractions, samples were prepared and stored in air- and light-proof flasks at $4^{\circ} \mathrm{C}$.

\section{In vitro digestion and fermentation of wheat aleurone}

Wheat aleurone (European and American) was digested and fermented in vitro according to the described procedures of Aura et al. $^{(22)}$ and Glei et al. $^{(5)}$ with some modifications ${ }^{(20)}$. The whole procedure was done in six repetitions using a batch-culture system. Briefly, for simulation of the whole digestive tract, samples were weighed $(0.5 \mathrm{~g}$ fermentable sample), mixed thoroughly with $10 \mathrm{ml}$ PBS $(0 \cdot 1 \mathrm{M} ; \mathrm{pH} 7 \cdot 0)$, and $0.85 \%(\mathrm{w} / \mathrm{v})$ saline solution $(6.25 \mathrm{ml})$ was added to the samples. A sample without wheat aleurone was used (blank; faeces control) as a control. All incubation steps were performed at $37^{\circ} \mathrm{C}$ in a shaking water-bath under the same conditions. Salivary $\alpha$-amylase (Sigma A-0521; Sigma-Aldrich, Steinheim, Germany) diluted to $1000 \mathrm{U} / \mathrm{ml}$ with $20 \mathrm{~mm}$-sodium phosphate buffer was added (17.36 U/sample), and the samples were incubated for $5 \mathrm{~min}$. $\mathrm{HCl}$ solution $(150 \mathrm{mM} ; 2.81 \mathrm{ml})$ was added to lower the $\mathrm{pH}$ to 2.0. Pepsin (Sigma P-7012; $1.11 \mathrm{mg}$ ) dissolved in $0.94 \mathrm{ml}$ of $20 \mathrm{~mm}-\mathrm{HCl}$ solution per sample or blank was added and the mixture was incubated for $2 \mathrm{~h}$. An intestinal extract was produced by dissolving $3 \mathrm{mg}$ ox gall (Fluka-Sigma 70168 ) and $2.6 \mathrm{mg}$ pancreatin (Sigma $\mathrm{P}-1750)$ in $5 \mathrm{ml}$ sodium bicarbonate buffer (11 mM; pH 6.5). The intestinal extract was added to each sample or blank, the $\mathrm{pH}$ was adjusted to 6.5 using $\mathrm{NaOH}$ solution $(10 \mathrm{M})$ and the suspension $(25 \mathrm{ml})$ was filled into a dialysis tube (4596.1, molecular weight cut-off 1000 Da; Roth, Karslsruhe, Germany). The tubes were placed into glass bottles filled with 2 litres dialysis buffer $(13.61 \mathrm{~g}$ potassium phosphate and $1.88 \mathrm{~g}$ sodium bicarbonate dissolved in distilled water; $\mathrm{pH} 6.5)$ and incubated for $6 \mathrm{~h}$ at $37^{\circ} \mathrm{C}$ under semi-anaerobic conditions. Semi-anaerobic conditions in the glass bottles were achieved by removing a part of the air with an injected cannula $(0.5$ bar for $1 \mathrm{~min})$. Subsequently, the bottles were filled with a fermentation gas mixture $\left(86 \% \mathrm{~N}_{2}, 10 \% \mathrm{CO}_{2}\right.$ and $\left.4 \% \mathrm{H}_{2}\right)$ via the cannula $(0.8$ bar for $1 \mathrm{~min})$. After $15 \mathrm{~min}$ (seven cycles repeated), the cannulae were removed. At the end of the incubation, the suspension was transferred from the dialysis tube into a $500 \mathrm{ml}$ glass bottle and the $\mathrm{pH}$ was measured for each sample.

The in vitro fermentation was performed as described by Glei et al. ${ }^{(5)}$ with slight modifications. At least three human donors provided faeces for the preparation of the faecal inoculums. All fermentations were conducted under anaerobic conditions at $37^{\circ} \mathrm{C}$ for $24 \mathrm{~h}$ (thirteen or fourteen cycles of removing the air and filling with the fermentation gas mixture). The fermentation process was stopped by placing the suspensions on ice and the $\mathrm{pH}$ was measured. Each sample was transferred to $50 \mathrm{ml}$ tubes and centrifuged $\left(4200 \mathrm{~g} ; 4^{\circ} \mathrm{C}\right)$ for $30 \mathrm{~min}$. The supernatant fractions were transferred into new $50 \mathrm{ml}$ tubes and centrifuged again $\left(4200 \mathrm{~g} ; 4^{\circ} \mathrm{C}\right)$ for $15 \mathrm{~min}$ and stored at $-80^{\circ} \mathrm{C}$. Before sterilisation of the fs, the samples were thawed quickly, sampled in $2 \mathrm{ml}$ tubes and centrifuged $\left(16000 \mathrm{~g} ; 4^{\circ} \mathrm{C}\right)$. Afterwards, the fs were sterilised by filtration (pore size $0.22 \mu \mathrm{m}$ ) to obtain the final fs for use in the cell-culture experiments and chemical analysis. The chemical analyses of the sterile fs were done by using HPLC-MS/MS and GC-MS and the results have been published before in Borowicki et al. ${ }^{(20)}$. Moreover, before incubation of the respective colon cells the sterilised fs were diluted with cell-culture medium to reach a final concentration of 5,10 or $20 \%(\mathrm{v} / \mathrm{v})$ fs. 


\section{Preparation of the synthetic mixtures}

The synthetic SCFA mixtures (of the fs of blank and aleurone) were prepared based on the concentrations determined by $\mathrm{GC}-\mathrm{MS}^{(20)}$. These mixtures thus mimic the exact concentrations of acetate, propionate and butyrate found in the different fs. The use of these samples in cell-culture experiments can help to identify the role of the respective SCFA in the biological effects of the fs. The same dilutions of the synthetic mixtures as the fs $(10 \%)$ were used in the cell-culture experiments.

The different SCFA were dissolved in Dulbecco's modified Eagle's medium (Gibco BRL, Eggenstein, Germany) supplemented with $10 \%$ fetal calf serum. Sodium butyrate (Chemical Abstracts Service (CAS) no. 156-54-7) and sodium acetate (CAS no. 127-09-3) were obtained from Merck-Schuchardt (Hohenbrunn, Germany). Sodium propionate (CAS no. 137-40-6) was from Sigma-Aldrich Chemie GmbH (Steinheim, Germany). All chemicals were of the highest commercially available grade of purity.

\section{Cell culture}

The culture conditions of human colon adenocarcinoma cell line HT29 (American Type Culture Collection (ATCC) no. HTB-38) were previously described in Glei et al. ${ }^{(23)}$. Passages 6-24 were used for the experiments. At regular intervals a mycoplasma test (MycoAlert ${ }^{\mathrm{TM}}$ Detection Kit; Lonza AG, Köln, Germany) was performed and contamination with mycoplasma was excluded.

\section{Isolation and cultivation of human epithelial stripes}

Colon epithelial stripes were isolated from tissue specimens obtained during surgery of colorectal tumours, diverticulitis and colon polyps. The tissues were taken from the very edges of the resected colon segments. After histological examination the surgeon confirmed that they did not show any micro- or macroscopic signs of malignant or inflammatory pathology. The university ethics committee approved the study and patients gave their informed consent (approval no. 1601-08/05). The mean age of the six donors whose colon epithelial stripes were used for cytosol preparation was 65 (SD 11) years. Of the donors, three were male. For gene expression analysis only five donors (three male, two female) could be used because of degradation of one sample during cDNA synthesis. The tissue was prepared by separating the colon epithelium from the underlying layers of the tissue according to a described procedure of Schaeferhenrich et $a l .{ }^{(24)}$. Resulting epithelial stripes were used for incubation and subsequent analysis of gene expression and enzyme activities. Tissue stripes were used because they displayed an improved survival after incubation in comparison with single cells in suspension.

\section{Treatment of colon epithelial stripes for analysis of gene expression and enzyme activity}

Effects on gene expression and enzyme activity in epithelial stripes were studied after incubating the tissue stripes with 10 and $20 \%$ (subtoxic concentrations diluted in medium) fs of the blank and fs of European aleurone for $10 \mathrm{~h}$. Because of the small size of the available samples, only the fs of European aleurone could be examined. Therefore, epithelial tissue stripes were placed in Petri dishes $\left(35 \mathrm{~mm}^{2}\right)$ and, after allowing the tissue pieces to settle for $15 \mathrm{~min}$, they were treated with the fs dissolved in minimal essential medium (MEM) with Earle's salts enriched with $20 \%$ fetal calf serum, 2 mM-glutamine, $1 \%$ penicillin/streptomycin, gentamicin $(100 \mu \mathrm{g} / \mathrm{ml})$, fungizone $(2.5 \mu \mathrm{g} / \mathrm{ml})$, epidermal growth factor $(10 \mathrm{ng} / \mathrm{ml})$, insulin $(5 \mu \mathrm{g} / \mathrm{ml})$, transferrin $(5 \mu \mathrm{g} / \mathrm{ml})$ and sodium selenite $(5 \mathrm{ng} / \mathrm{ml})^{(25)}$. After $10 \mathrm{~h}$, epithelial stripes were washed and immediately submerged in RNAlater RNA stabilisation reagent (Qiagen, Hilden, Germany) or they were ground in liquid $\mathrm{N}_{2}$ for enzyme activity measurement. The epithelial stripes were stored at $-80^{\circ} \mathrm{C}$ until further use for total RNA isolation and cytosole extraction.

Treatment of HT29 cells for analysis of gene expression, enzymic activity and anti-genotoxicity

HT29 cells were grown in $\mathrm{T}_{25}$ cell-culture flasks $\left(3 \times 10^{6}\right.$ cells per flask) for gene expression analysis using custom array or real-time PCR and in six-well plates $\left(1.5 \times 10^{6}\right.$ cells per well) for analysis of enzyme activity and anti-genotoxic capacity for $24 \mathrm{~h}$. Thereafter they were treated with $10 \%$ fs of aleurone (European and American) for $24 \mathrm{~h}$ (gene expression) or $24-72 \mathrm{~h}$ (enzyme activity), respectively, and with 5 and $10 \%$ of fermented aleurone for $24-48 \mathrm{~h}$ (anti-genotoxicity). In addition, for the analyses of enzyme activities, HT29 cells were also incubated with the corresponding synthetic SCFA mixture of each complex fs or butyrate alone. Moreover, a positive control (4 mM-butyrate) was used for gene expression analysis (real-time PCR only). After incubation, the HT29 cells were trypsinised and suspended in PBS. Viability and cell number were determined with a CASY-cell counter (CASY $^{\circledR}$ model TT; Roche Innovatis AG CASY ${ }^{\circledR}$ Technology, Bielefeld, Germany). Subsequently, the cells were used for investigations on mRNA expression, enzyme activity and anti-genotoxicity.

\section{Isolation of RNA}

To isolate total RNA, epithelial stripes stored in RNAlater solution were thawed and transferred into RLT (lysis) buffer. Subsequently, the cell pellets were homogenised in the presence of RLT buffer using the Polytron PT-DA 2107/ 2EC Homogenizer (Fisher Scientific GmbH, Nidderau, Germany). HT29 cells stored in RLT buffer were thawed and lysed using QIAshredder mini spin columns.

Thereafter, total RNA was isolated using the RNeasy Plus Mini Kit according to the manufacturer's manual (Qiagen, Hilden, Germany). Total RNA (dissolved in $50 \mu$ l RNasefree water) was stored at $-80^{\circ} \mathrm{C}$. Yield and purity of RNA were determined with the NanoDrop ${ }^{\circledR}$ ND-1000 Spectrophotometer (Peqlab, Erlangen, Germany) and RNA quality (RNA integrity number; RIN) was measured using the Bioanalyzer (Agilent Technologies Deutschland $\mathrm{GmbH}$, Böblingen, Germany). 


\section{mRNA expression analysis using custom array}

To analyse a broad range of genes involved in mechanisms of carcinogenesis and chemoprevention, a custom-designed cDNA microarray was used for HT29 cells.

For this, equal amounts of RNA (1 $\mu \mathrm{g}$; RIN 8.5-10) were used for synthesising first-strand cDNA with Superscript II RT (Invitrogen GmbH, Karlsruhe, Germany). A secondstrand cDNA was synthesised afterwards using Polymerase I, RNaseH and Escherichia coli DNA ligase (Invitrogen $\mathrm{GmbH})$. After clean-up of the product, the double-stranded cDNA was used to synthesise cRNA by in vitro transcription in order to increase the amount of template used for cDNA labelling with Cy3- and Cy5-dCTPs (GE Healthcare, Braunschweig, Germany). The reaction product was purified to obtain clean, labelled and single-stranded cDNA which was hybridised with a customised cDNA array (PIQOR; Miltenyi Biotec, Bergisch-Gladbach, Germany) containing 300 genes which are involved in colon cancer and six housekeeping genes as described previously ${ }^{(26)}$. Before this, the glass slide arrays were preheated and prehybridised. The final hybridisation step was carried out overnight in a humidified hybridisation chamber at $65^{\circ} \mathrm{C}$. After this, the custom arrays were washed and dried before scanning and measuring fluorescence intensity which was done by Miltenyi Biotec (Bergisch-Gladbach, Germany). LOESS (locally weighted scatterplot smoothing)-corrected raw data were normalised to the housekeeping gene glyceraldehyde 3-phosphate dehydrogenase $(G A P D H)$. Data are presented as fold change compared with the medium control which was set to 1 for each experiment.

\section{mRNA expression analysis of CAT, GST, MAF2 and} SULT2B1 using real-time PCR

For the analysis of gene expression, $1 \mu \mathrm{g}$ (epithelial stripes) or $2.5 \mu \mathrm{g}$ (HT29 cells) of total RNA (RIN: epithelial stripes, 7-10; HT29, 9-10) were converted into first-strand cDNA using SuperScript II (Invitrogen $\mathrm{GmbH}$ ) and an oligo(dT) ${ }_{12-18}$ primer. Real-time quantitative PCR (qPCR) was carried out using specific primer pairs and qPCR Eva Green Master (Jena Bioscience, Jena, Germany). All reactions were performed in duplicate. The PCR reaction profile included an initial denaturation of $2 \mathrm{~min}$ at $95^{\circ} \mathrm{C}$, followed by forty cycles of denaturation $\left(15 \mathrm{~s}\right.$ at $\left.95^{\circ} \mathrm{C}\right)$, annealing and extension $\left(30 \mathrm{~s}\right.$ at $\left.60^{\circ} \mathrm{C}\right)$. Cumulative fluorescence was measured at the end of the extension of each cycle. Product-specific amplification was confirmed by melting curve analysis. The following gene-specific primer sequences were used for the quantification: $C A T$ (forward 5'-TGGACAAGTACAATGCTGAG-3' and reverse $5^{\prime}$-TTACACGG ATGAACGCTAA G-3'); GAPDH (forward 5'-ACCCACTCCTCCACCTTTGAC-3 ${ }^{\prime}$ and reverse $5^{\prime}$-TCCACCACCCTGTTGCTGTAG- ${ }^{\prime}$ ); GSTP1 (forward 5'-CTGCGCATGCTGCTGGCAGAT C-3' and reverse $5^{\prime}$-TTGGACTGGTACAGGGTGAGGTC-3'); $M A F 2$ (forward 5'-AAATACGA GAAGTTGGTGAGCAG-3' and reverse ACACTGGTAAGTACACGATGCTG-3'); SULT2B1 (forward, 5'-ACGACGACATCTTTAT-CATCAC-3' and reverse, $5^{\prime}$-CATGTAGATCACCTTGGC CT-3'). All primers were designed using the freely available PerlPrimer software v1.1.17 (http://perlprimer.sourceforge.net). Gene expression of target genes was calculated on the basis of the housekeeping gene glyceraldehyde 3-phosphate dehydrogenase (GAPDH) according to Pfaffl et al. ${ }^{(27)}$. Changes of expression were determined as the fold change compared with the medium control which was set to 1 .

\section{Preparation of cell lysates and measurement of enzyme activities}

Briefly, after harvesting and washing, cytosols of HT29 cells were extracted by incubation in a lysis buffer containing $1 \mathrm{~mm}$-EDTA, $0.1 \%$ Triton X-100, $50 \mathrm{mm-potassium} \mathrm{phos-}$ phate buffer ( $\mathrm{pH} 6.5)$ and $1 \mathrm{~mm}$-pefabloc (Roth, Karlsruhe, Germany) for $10 \mathrm{~min}$ on ice. Epithelial stripes were thawed and homogenised before cytosol extraction in the presence of the lysis buffer using a Polytron PT-DA 2107/2EC Homogenizer (Fisher Scientific GmbH, Nidderau, Germany). Cells were subsequently incubated for $10 \mathrm{~min}$ on ice. After centrifugation $\left(10000 \mathrm{~g} ; 10 \mathrm{~min} ; 4^{\circ} \mathrm{C}\right)$, the supernatant fractions were sampled and subsequently used for enzyme activity measurements. CAT activity was calculated according to Aebi et al. using $\mathrm{H}_{2} \mathrm{O}_{2}$ as substrate ${ }^{(28)}$. The decrease of $\mathrm{H}_{2} \mathrm{O}_{2}$ was photometrically measured at $240 \mathrm{~nm}$ and $22^{\circ} \mathrm{C}$. Total GST activity was determined photometrically as described in Habig et al. ${ }^{(29)}$ using 1-chloro-2,4-dinitrobenzene (CDNB) as substrate. The increase of the $S$-2,4-dinitrophenylglutathione, the product of conjugated CDNB, was measured at $340 \mathrm{~nm}$ and $30^{\circ} \mathrm{C}$ using a photometer. Results were calculated on the basis of $1 \times 10^{6}$ cells for HT29 cells and expressed as fold change compared with the medium control which was set to 1. Opposed to this, enzyme activities of epithelial stripes were calculated on the basis of $1 \mu \mathrm{g}$ protein because tissue stripes were incubated and thus the determination of cell number was not possible. Afterwards, the results were expressed as fold change compared with the medium control which was set to 1 . Total protein content was measured using the method of Bradford with bovine serum albumin as the standard protein ${ }^{(30)}$.

\section{Detection of anti-genotoxicity}

DNA damage was measured with the single cell micro gel electrophoresis (comet assay) after challenging the fs of aleurone pre-incubated cells with $75 \mu \mathrm{M}-\mathrm{H}_{2} \mathrm{O}_{2}$ for $15 \mathrm{~min}$ at $37^{\circ} \mathrm{C}$ as has been described elsewhere ${ }^{(31)}$. Comet images, revealing the amount of damaged DNA (intensity of fluorescence in the comet tail; \% tail intensity) ${ }^{(32)}$, were quantified using the image analysis system of Perceptive Instruments (Halstead, Essex, UK). For each concentration, means of sixty cells were the basis for calculating the effects in one experiment.

\section{Statistical evaluation}

Mean values and standard deviations were calculated from at least three independent experiments (HT29 cells) and five or six donors (colon epithelial stripes), respectively. Differences were calculated by one- or two-way ANOVA, including the Bonferroni post test with selected pairs, or by Student's $t$ test using GraphPad Prism (version 5.02 for Windows; GraphPad 


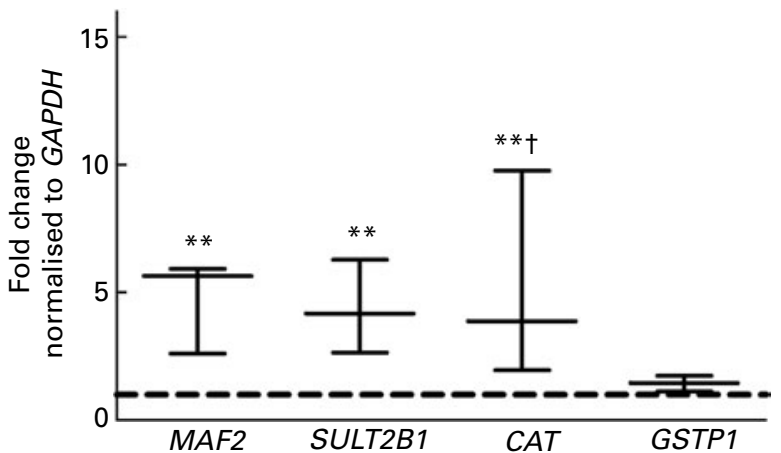

Fig. 1. Gene expression analysis using customised cDNA array in HT29 cells after treatment with $10 \%$ of the fermentation supernatant fraction (fs) of European aleurone for $24 \mathrm{~h}$. GAPDH, glyceraldehyde 3-phosphate dehydrogenase; $M A F 2$, transcription factor MAF (proto-oncogene C-MAF); SULT2B1, sulfotransferase family cytosolic $2 \mathrm{~B}$ member 1 ; CAT, catalase; GSTP1, glutathione S-transferase pi 1. Data are expressed as box and whisker plots (median values and variations; $n 3$ ). Mean value was significantly different from that of the medium control (set to $1 ;---)$ : ${ }^{* *} P<0.05$ (Student's $t$ test). Mean value was different from that of the fs of the blank (data not shown): $\uparrow P<0.10$ (trend; Student's $t$ test)

Software, San Diego, CA, USA). The statistical analyses used depended on the respective experimental design and are specified in the legends to the figures and table footnotes.

\section{Results}

\section{Effects of fermented aleurone on mRNA expression in HT29 cells}

To analyse the effects of the fs of European aleurone on the expression of a broad range of genes a custom array was used. The results indicated that the expression of ten genes was significantly $(P<0.05 ; t$ test $)$ up-regulated on the basis of the evaluation criteria $(\leq 0 \cdot 6, \geq 1 \cdot 5)$ after treatment with $10 \%$ fs of European aleurone for $24 \mathrm{~h}$. No gene was significantly down-regulated. The regulated genes are involved in phase II and phase III metabolism as well as stress response and signal transduction and cell-cycle regulation. Of the significantly modulated genes (Fig. 1), three, namely $C A T$, $M A F 2$ and $S U L T 2 B 1$, which were of special interest for primary prevention, were verified by real-time PCR.
In addition, the mRNA expression of GSTP1, which was induced 1.4 (SD 0.3) fold in comparison with the medium control, was measured. Although its induction was not significant, GSTP1 was of special interest because it is the main GST isoform in the colon. The fs of the blank showed no modulation of mRNA expression (data not shown).

\section{Confirmatory experiments using real-time quantitative PCR in HT29 cells}

The induction of the selected genes (CAT, GSTP1, MAF2 and $S U L T 2 B 1)$ after the incubation with $10 \%$ fs of aleurone (European and American) was evaluated by real-time qPCR. The directional changes in mRNA expression levels in response to the fs of European aleurone after $24 \mathrm{~h}$ were confirmed except for $M A F 2$ for which no functional primer pair could be established. In addition, American aleurone, which was not investigated in the custom array analysis, showed a comparable modulation. The regulation by both fs of aleurone after $24 \mathrm{~h}$ is displayed in Fig. 2. Thus, expression levels of all three genes were significantly increased, with a fold change of over 1.5 in comparison with the medium control. Moreover, the up-regulation of $C A T$ and GSTP1 by both fs of aleurone was significantly different from the faeces control (fs of blank; sample without test substance). Interestingly, for SULT2B1 the expression was induced by the fs of the blank on a significantly higher level than by the fs of aleurone.

\section{Gene expression analysis of CAT and GSTP1 in colon epithelial stripes with real-time quantitative PCR}

To analyse if aleurone can also increase the expression of genes involved in primary chemoprevention in healthy colon cells and thus prevent the initiation of cancer, we used colon epithelial stripes isolated from human colon surgeries. The mRNA expression of selected genes involved in pathways of antioxidative defence $(C A T)$ and detoxification of carcinogens (GSTP1) was investigated using real-time qPCR.

In comparison with HT29 cells, in epithelial stripes only the mRNA expression of GSTP 1 was significantly induced by the fs of aleurone (10\%, 1.6 (SD 0.3) fold; $20 \%, 1.8$ (SD 0.5) fold) (Fig. 3) whereupon the up-regulation by $10 \%$ fs of aleurone was more effective than the respective fs of the blank.
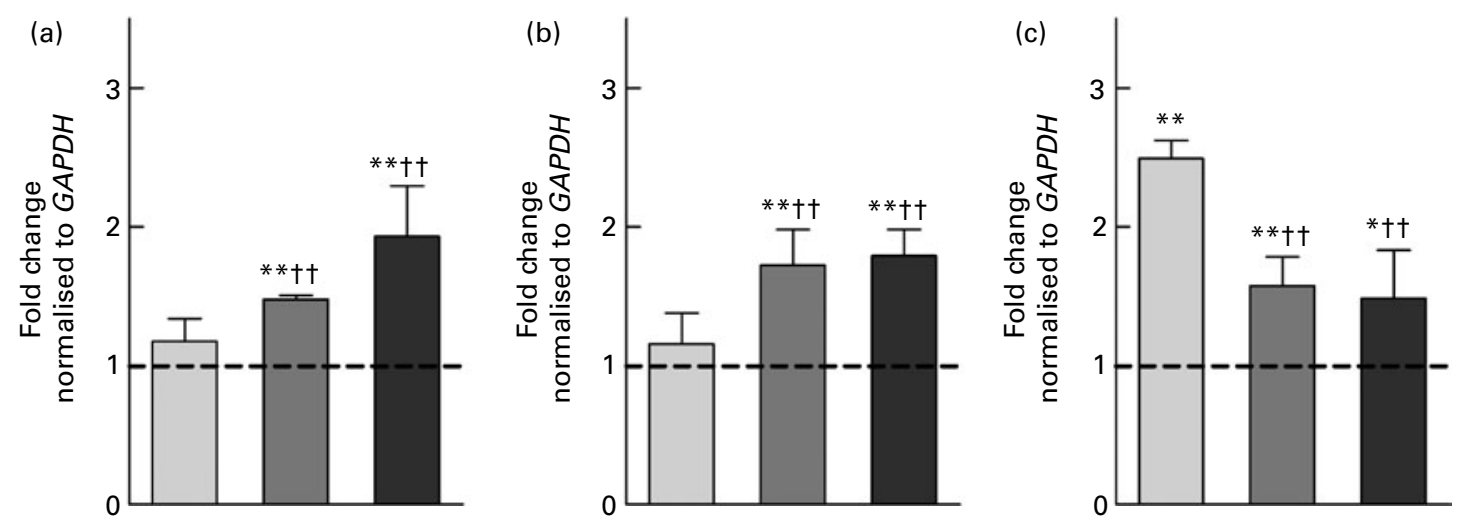

Fig. 2. Gene expression analysis of catalase (CAT) (a), glutathione S-transferase pi 1 (GSTP1) (b) and sulfotransferase family cytosolic 2B member 1 (SULT2B1) (c) using real-time quantitative PCR in HT29 cells after incubation with $10 \%$ of the fermentation supernatant fraction (fs) of the faeces control (blank) ( $\square$ ), the European ( $\square$ ) and the American aleurone $(\square)$ after $24 \mathrm{~h}$. Values are means $(n 3)$, with standard deviations represented by vertical bars. Mean value was different from that of the medium control (set to $1 ;---)$ : * $P<0.10$ (trend), ${ }^{* *} P<0.05$ (Student's $t$ test). Mean value was significantly different from that of the fs of the blank: $\dagger \dagger P<0.05$ (Student's $t$ test). 

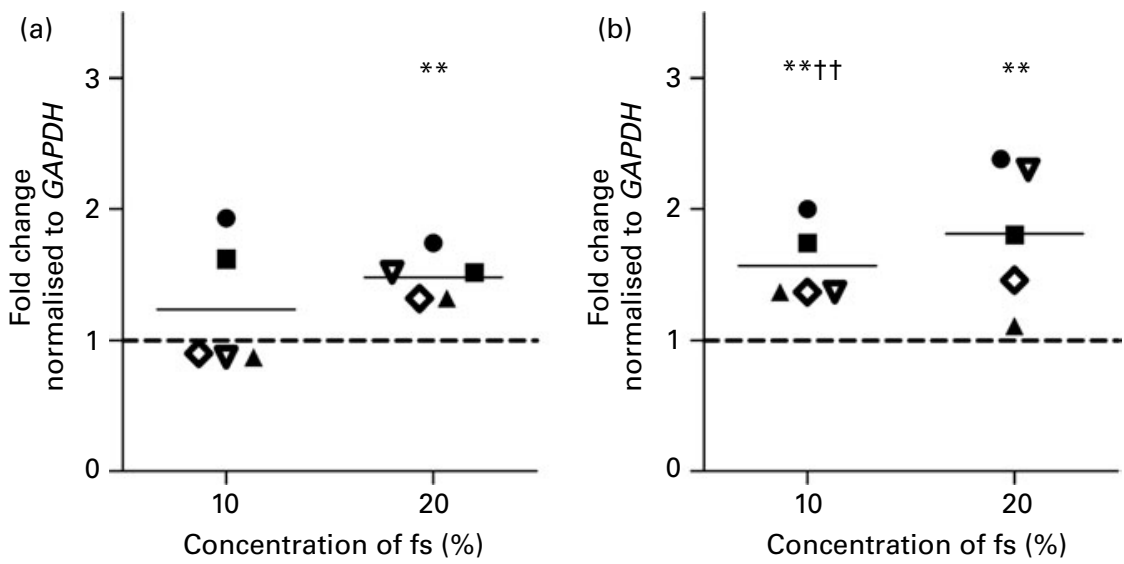

Fig. 3. Gene expression analysis of glutathione S-transferase pi 1 (GSTP1) using real-time quantitative PCR in human colon epithelial stripes after incubation with 10 and $20 \%$ of the fermentation supernatant fraction (fs) of the faeces control (blank) (a) and the European aleurone (b) for $10 \mathrm{~h}$. Results are normalised based on glyceraldehyde 3-phosphate dehydrogenase $(G A P D H)$, calculated compared with the medium control (set to 1 ; - - -) and expressed as fold change. Shown are the means of five donors (-) and the variability of response of each donor. The same symbols represent the response in one donor. Mean value was significantly different from that of the medium control: ${ }^{*} P<0.05$ (Student's $t$ test). Mean value was significantly different from that of the fs of the blank: $† \dagger P<0.05$ (Student's $t$ test).

Moreover, the fs of the blank altered the mRNA expression at a concentration of $20 \%$ ( 1.5 (SD 0.2$)$ fold). For CAT no modulation of the mRNA expression level was seen (data not shown).

\section{Quantification of total glutathione S-transferase activity}

To verify whether the observed changes in gene expression would have an effect on the functional level, GST activity, a marker of cancer chemoprevention, was measured in HT29 and human colon epithelial stripes. Therefore, HT29 cells were incubated with $10 \%$ fs of aleurone (European and American), the corresponding synthetic SCFA mixture and butyrate for 24,48 and $72 \mathrm{~h}$ while the epithelial stripes were incubated with 10 and $20 \%$ of the fs of aleurone (European) for $10 \mathrm{~h}$. In HT29 cells the GST activity was significantly enhanced by fermented American aleurone after an incubation time of $48 \mathrm{~h}$ whereas a non-significant trend for the induction by European aleurone was observed $(P=0.08 ; t$ test $)$. The longer incubation time $(72 \mathrm{~h})$ with the fs of European and American aleurone did not result in higher levels of GST activity (data not shown) so that only effects after $48 \mathrm{~h}$ are illustrated in Table 1 (relative GST activity column). Only the fs of American aleurone differed from the fs of the blank, after $48 \mathrm{~h}$ by trend $(P<0.07)$ and after $72 \mathrm{~h}$ on a significant level even though no differences in induction of enzyme activity were seen for both varieties. Enzyme activity was not affected by the fs of the blank in comparison with the medium control. The synthetic mixture (SCFA) of the complex fs of American aleurone and butyrate also induced GST activity after $48 \mathrm{~h}$ in HT29 cells in a comparable manner, but on a significantly lower level than the fs.

In epithelial stripes GST enzyme activity was significantly increased by both $10 \%$ fs of the blank and fs of aleurone on a low level (Fig. 4). Furthermore, the fs of the blank and fs of aleurone showed a comparable activity.

\section{Quantification of catalase activity}

As a further marker for cancer prevention, CAT activity was determined in HT29 and epithelial stripes using the different test substances. The quantification revealed that CAT activity was induced in HT29 cells in response to the incubation with the fs of the blank, fs of aleurone as well as the corresponding synthetic mixtures and butyrate. Already, after $24 \mathrm{~h}$ the fs of European aleurone significantly modulated CAT activity in comparison with the medium control. This effect became more pronounced over time, so that after $72 \mathrm{~h}$ the enzyme activity was 2.7 (SD 0.68) fold increased. The inducing effect could also be seen for American aleurone which became significant after the incubation for 48 and $72 \mathrm{~h}$, being strongest after $72 \mathrm{~h}(3.3$ (SD 1.76) fold). Since the effects were strongest after incubation for $72 \mathrm{~h}$, data are only illustrated for this time point in Table 1 (relative CAT activity column). Differences from the fs of the blank were significant

Table 1. Glutathione $S$-transferase (GST) activity after $48 \mathrm{~h}$ and catalase (CAT) activity after $72 \mathrm{~h}$ treatment of HT29 cells with the fermentation supernatant fractions (fs) and their identical synthetic SCFA mixtures and butyrate§

(Mean values and standard deviations; $n 4$ )

\begin{tabular}{|c|c|c|c|c|}
\hline & \multicolumn{2}{|c|}{$\begin{array}{l}\text { Relative GST } \\
\text { activity } \\
\text { (fold change) }\end{array}$} & \multicolumn{2}{|c|}{$\begin{array}{c}\text { Relative CAT } \\
\text { activity } \\
\text { (fold change) }\end{array}$} \\
\hline & Mean & SD & Mean & SD \\
\hline fs of blank & 1.3 & $0 \cdot 6$ & 1.4 & 0.7 \\
\hline SCFA & $1 \cdot 1$ & $0 \cdot 2$ & $1 \cdot 0$ & 0.1 \\
\hline Butyrate & $1 \cdot 2$ & 0.2 & $1 \cdot 0$ & 0.2 \\
\hline fs of European aleurone & $2 \cdot 2^{*}$ & 1.0 & $2 \cdot 6^{\star *} \dagger \dagger$ & 0.6 \\
\hline SCFA & $1 \cdot 1$ & 0.3 & $1 \cdot 5^{\star \star} \neq \ddagger$ & 0.3 \\
\hline Butyrate & $1 \cdot 2$ & $0 \cdot 2$ & $1 \cdot 3$ & 0.3 \\
\hline fs of American aleurone & $2 \cdot 2^{* \star} \dagger$ & 0.5 & $3 \cdot 7^{\star \star} \dagger$ & 1.7 \\
\hline SCFA & $1 \cdot 3^{\star \star} \neq \ddagger$ & $0 \cdot 1$ & $1.4^{\star \star} \ddagger$ & 0.1 \\
\hline Butyrate & $1 \cdot 5^{\star \star} \ddagger$ & 0.3 & $1.5^{\star \star} \ddagger$ & 0.3 \\
\hline
\end{tabular}

Mean value was different from that of the medium control (set to 1 ): ${ }^{*} P<0.10$ (trend), ${ }^{\star *} P<0.05$ (Student's $t$ test).

Mean value was different from that of the fs of the blank: $\dagger P<0.10$ (trend), †† $P<0.05$ (Student's $t$ test).

Mean value was different from that of the respective fs: $\ddagger P<0.10$ (trend), $\ddagger \ddagger P<0.05$ (Student's $t$ test).

$\S$ Results are calculated compared with the medium control and expressed as fold change. 

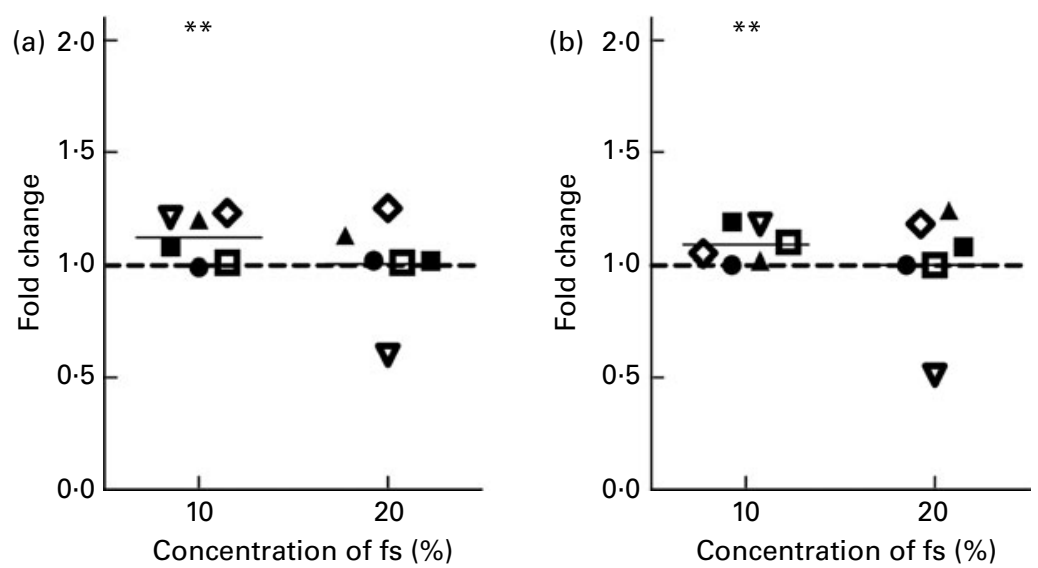

Fig. 4. Enzyme activity of glutathione $S$-transferase in human colon epithelial stripes after incubation with 10 and $20 \%$ of the fermentation supernatant fraction (fs) of the faeces control (blank) (a) and the European aleurone (b) for $10 \mathrm{~h}$. Results are calculated compared with the medium control (set to $1 ;---)$ and expressed as fold change. Shown are the means of six donors $(-)$ and the variability of response of each donor. The same symbols represent the response in one donor. Mean value was significantly different from that of the medium control: ** $P<0.05$ (Student's $t$ test).

for the fs of European aleurone and showed a trend for the fs of American aleurone only after $72 \mathrm{~h}$. Enzyme activity was not affected by the fs of the blank in comparison with the medium control after $72 \mathrm{~h}$. Particularly after $72 \mathrm{~h}$, the corresponding synthetic mixtures (SCFA) of fermented aleurone (European and American) induced CAT activity even though at a lower level than the fs. Moreover, butyrate alone also enhanced enzyme activity and did not vary from the synthetic SCFA mixture. In epithelial stripes CAT enzyme activity was significantly increased by $10 \%$ fs of aleurone (1.4 (SD 0.4) fold) after $10 \mathrm{~h}$ even though the effect was not significantly different from the fs of the blank, which also stimulated enzyme activity on a significant level (Fig. 5).

\section{Anti-genotoxicity}

To analyse whether treatment with fermented aleurone caused an improved protection against oxidative stress, HT29 cells were pre-incubated for 24 and $48 \mathrm{~h}$ with the test compounds and afterwards they were challenged with $\mathrm{H}_{2} \mathrm{O}_{2}$. No cytotoxic

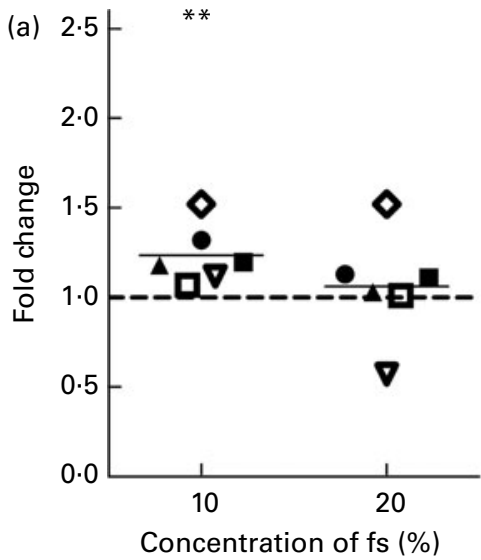

impact of either substance was detected at the applied concentration and time. Treatment with the fermented aleurone (European and American) resulted in significantly reduced levels of $\mathrm{H}_{2} \mathrm{O}_{2}$-induced DNA damage after $48 \mathrm{~h}$ (Fig. 6). However, DNA damage was also reduced at a comparable level by the fs of the blank. After $24 \mathrm{~h}$ pre-incubation DNA damage was not affected by the fs of European and American aleurone. No DNA damage was detected in medium-incubated control cells or cells incubated with the fs of aleurone (European and American) and the fs of the blank, demonstrating that these samples had no genotoxic effects (data not shown).

\section{Discussion}

It has been proposed that dietary habits and lifestyle strongly affect the development of colorectal cancer ${ }^{(33)}$. However, it is still a matter of debate whether dietary fibre actually plays an important role in colon cancer prevention ${ }^{(34-36)}$.

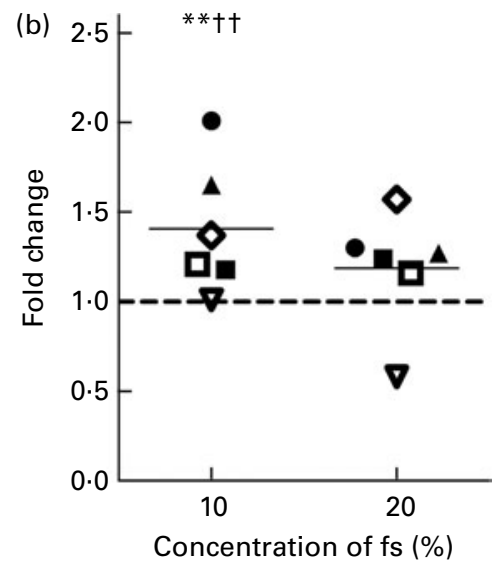

Fig. 5. Enzyme activity of catalase in human colon epithelial stripes after incubation with 10 and $20 \%$ of the fermentation supernatant fraction (fs) of the faeces control (blank) (a) and the European aleurone (b) for $10 \mathrm{~h}$. Results are calculated compared with the medium control (set to 1 ; ---) and expressed as fold change. Shown are the means of six donors $(-)$ and the variability of response of each donor. The same symbols represent the response in one donor. Mean value was significantly different from that of the medium control: ${ }^{\star *} P<0.05$ (Student's $t$ test). Mean value was significantly different from that of the fs of the blank: †† $P<0.05$ (Student's $t$ test). 


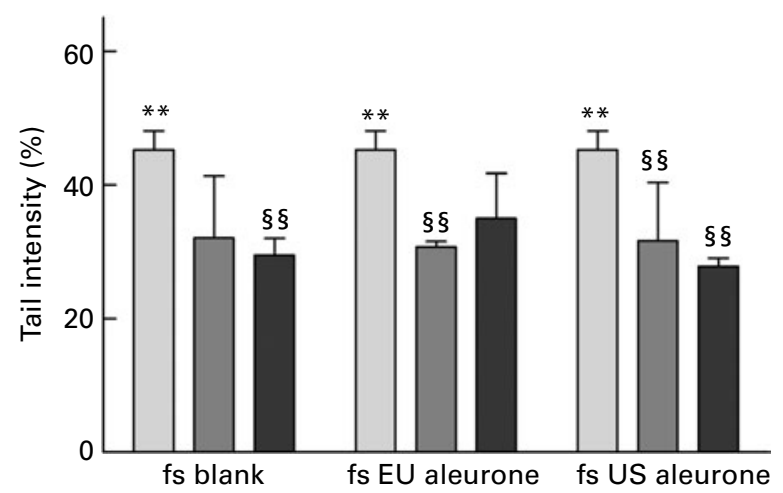

Fig. 6. Modulation of $\mathrm{H}_{2} \mathrm{O}_{2}$-induced DNA damage by pre-treatment with 0 $(\square), 5$ ( $\square$ ) and $10 \%$ ( $\square$ ) fermentation supernatant fractions (fs) of faeces control (blank), European (EU) aleurone and American (US) aleurone for $48 \mathrm{~h}$ in HT29 cells. Values are means ( $n 3)$, with standard deviations represented by vertical bars. Mean value was significantly different from that of the medium control: ${ }^{\star *} P<0.05$ (Student's $t$ test), $\S \S P<0.05$ (one-way ANOVA with Bonferroni post test).

The involvement of complex fs and their contained fermentation products, especially of butyrate, on markers of primary prevention was until today rarely the subject of in vitro studies. The custom array results of the present study showed a significant induction of genes involved in the mechanisms of detoxification of xenobiotics and drugs ${ }^{(37,38)}$, for example, GSTP1 and SULT2B1, and their regulatory pathways, for example, $M A F 2$, as well as in the stress response, for example, $C A T$ by fermented European aleurone where $C A T$ was the most strongly affected gene (5.19 (SD 4.07) fold). Thus, a better protection of cells from DNA damage, risk of mutations and, possibly, promotion and progression of carcinogenesis can be suggested ${ }^{(39)}$. Although, the induction of GSTP1 mRNA expression, the major GST in the human colon epithelium ${ }^{(40)}$, was only visible as a trend, we detected a clear induction by real-time qPCR investigations.

Phase II enzymes are regulated by the transcription factor Nrf2. In response to oxidative stress, Nrf2 dissociates from its cytosolic inhibitor Keap1, translocates to the nucleus, forms a heterodimer with other bZIP transcription factors such as MAF2 (c-maf) ${ }^{(41)}$ and binds to the antioxidative response elements (ARE) in the promoters of target genes. This leads to the activation of the transcription of several defence genes such as GSTP1 and $C A T^{(42,43)}$. We measured an enhanced expression of MAF2 of about 4.73 (SD 1.84) fold after an incubation with $10 \%$ fs of European aleurone which may cause the higher expression of GSTP1 and $C A T^{(26,44)}$. However, much more in-depth studies are necessary to elucidate the underlying mechanisms in the regulation of GSTP1 and CAT mRNA expression by fermented aleurone.

The custom array results were confirmed using real-time qPCR in HT29 cells. The expressions of CAT, GSTP1 and $S U L T 2 B 1$ were significantly increased ( $\geq 1.5$ fold) by the fs of the European and American aleurone in a comparable manner, whereas the faeces control had no effect on the mRNA expression of CAT and GSTP1.

To analyse whether the fermentation samples can also protect healthy colon cells from carcinogens, we used human colon epithelial stripes. Here we found an induction of CAT mRNA expression by $20 \%$ fs of aleurone $(1.5$ (SD 0.6) fold). Studies of Sauer et al. ${ }^{(15)}$, who showed an induced mRNA expression of CAT (1.6 (SD 0.6) fold) by $10 \mathrm{~mm}$-butyrate, support this finding. However, the concentration of butyrate was about 5-fold lower in the fs and thus synergistic effects of butyrate with other unknown fermentation metabolites may increase the efficacy of the fs. It has to be kept in mind that epithelial stripes are isolated from human colon surgeries and therefore cells from different donors may react differently. This is supported by our findings showing that the CAT mRNA was expressed with a high interindividual variability in human colon epithelial stripes, which points to large differences in cellular susceptibility to xenobiotics between the donors. In addition, an induction of the GSTP1 mRNA expression by the fs (10 and $20 \%$ ), but also by the fs of the blank, was observed in the epithelial stripes, pointing to yet unidentified factors in the faecal matrix that may be responsible ${ }^{(45)}$. A study of Treptow-van Lishaut et al. also demonstrated an enhanced GSTPl mRNA expression in the colon of rats after feeding a diet rich in resistant starch $^{(46)}$. Pool-Zobel et al. ${ }^{(47)}$ showed an induction of several GST after butyrate treatment of human colon epithelial stripes, premalignant human LT97 adenoma and malignant human HT29 cancer cells. In this context, it was discussed that on one hand, an induction of GST is favourable since it results in an enhanced detoxification of risk factors in primary cells. On the other hand, in tumour cells the induction could increase resistance to chemotherapeutic agents. However, it may be speculated that the high concentration of butyrate $(10-20 \mathrm{mM})$ in vivo could impair tumour cell growth before GST induction can occur ${ }^{(47)}$. Nevertheless, the HT29 cell line has often been applied to investigate cancer-preventive effects of food constituents as a well-established cell model for human colon cells ${ }^{(20,23,48-50)}$ owing to the lack of manageable culture methods for primary cells.

Both the fs of European and American aleurone showed a significant induction of SULT2B1 mRNA expression (European, 1.6 (SD 0.2) fold; American, 1.5 (SD 0.3) fold). This effect was, however, also observed for the fs of the blank (2.5 (SD 0.1) fold). Saini et al. reported that cytosolic SULT-mediated sulfation plays an essential role in the detoxification of bile acids ${ }^{(51)}$. Thus, higher concentrations of toxic bile acids in the fs of the blank (cholic acid (CA), ${ }^{(20)}$ $0.35 \mu \mathrm{M}$; deoxycholic acid (DCA), 46.65 $\mu \mathrm{M}$ ) than in the fs of aleurone (European: CA, 0.20 $\mu \mathrm{M}$, DCA, 5.04 $\mu \mathrm{M}$; American: CA, $0.23 \mu \mathrm{M}$, DCA, 5.93 $\mu \mathrm{M}$ ) could possibly explain the slightly higher induction of SULT2Bl expression by the fs of the blank. We were not able to examine mRNA expression of $S U L T 2 B 1$ in epithelial stripes because of the small size and the limited availability of the colon surgery samples.

Measurements of enzyme activities as a possible consequence of increased mRNA expression showed an enhanced CAT and GST activity by $10 \%$ fs of aleurone (European and American) after 48 and $72 \mathrm{~h}$, respectively, in HT29 cells. Our investigations allow comparison of enzyme activity induction caused by the complex fs, synthetic SCFA mixture as well as butyrate alone in HT29 cells. Only the SCFA mixture and butyrate of the fs American aleurone, but not of European aleurone, were capable of inducing GST activity but on a lower level than the complex fs. An induction of GST activity by $4 \mathrm{~mm}$-butyrate has been previously demonstrated in human colon cancer cells ${ }^{(49,52)}$. In another study the induced GST activity by complex fs of arabinoxylans 
could be mainly attributed to the butyrate content ${ }^{(5)}$. Since the SCFA mixture and butyrate showed comparable effects, butyrate seems to be mainly responsible for the effects observed in the present study. However, the results indicate that interactions with other metabolites in the fs are obviously important. The so-called 'added value' of secondary plant compounds such as antioxidant and anti-mutagenic phenolic acids $^{(53)}$ in wheat aleurone could be the reason for the higher enzyme activity measured by the complex fs compared with the single fermentation product butyrate. The lack of induction of GST activity by the SCFA mixture and butyrate of the fs of European aleurone could be due to a lower butyrate concentration than in the fs of American aleurone (European, 2.0 mM; American, $2.4 \mathrm{~mm}$ ).

In human epithelial stripes the GST activity was significantly increased on a low level by the fs of aleurone, but also by the fs of the blank. Possibly a $10 \mathrm{~h}$ incubation was too short to detect unambiguous changes in protein expression levels. Therefore, an increase of the survival time of human epithelial stripes in culture, a major limitation of this interesting model of healthy colon cells, may be necessary to analyse effects on enzyme activities in detail. Efforts to improve models of healthy colon cells are therefore important to analyse effects of nutritional factors on markers of chemoprevention and a major focus of research of our and other groups. In addition, inhibitory substances in the faecal matrix could exist and influence GST activity, as was suggested by Beyer-Sehlmeyer et al. $^{(6)}$.

To date, no data are available whether complex fs affect CAT activity in vitro and in vivo. Furthermore, only relatively few data exist which describe an effect by butyrate treatment on CAT activity. Sauer et al. showed the induction of CAT activity by butyrate treatment $(10 \mathrm{~mm})$ in primary human colon cells ${ }^{(15)}$. In addition, studies of Yano \& Tierney demonstrated a butyrate-induced increase in CAT activity in artery smooth muscle cells ${ }^{(54)}$. Our investigation demonstrates for the first time that the induction of CAT is caused by fs of aleurone in HT29 cells. The corresponding SCFA mixture and butyrate also increased the enzyme activity, but on a lower level than the complex fs which indicates that various compounds, in particular phenolic acids ${ }^{(55)}$, of the fs rather than a single component such as butyrate possibly contribute to the effects in vitro.

Furthermore, in human epithelial stripes an enhanced CAT enzyme activity by the fs of aleurone (10\%, but not $20 \%$ ) significantly different from the fs of the blank was also observed. The fact that mRNA levels of $C A T$ are not modulated by the fs of aleurone possibly indicates that CAT activity can be the result of post-transcriptional modifications. The same was reported in investigations using primary colon cells by Sauer et al. who demonstrated an enhanced CAT activity after $2 \mathrm{~h}$ which was less apparent after 4 and $8 \mathrm{~h}$ while gene expression was increased after $12 \mathrm{~h}$ of butyrate treatment $(10 \mathrm{mM})^{(15)}$. The fs of the blank $(10 \%)$ also altered CAT enzyme activity (1.4 (SD 0.4) fold) when compared with the medium control, again possibly explicable by unidentified bacterial products $^{(45)}$. In addition, different susceptibilities of the donors again play a decisive role. While in some of the donors mRNA expression and/or enzyme activity (mainly donors 1, 2 and 4) was increased, in other donors no effects on these two parameters were observed.
The present study reports, as a further functional effect of the complex fermentation samples, that all fs and the fs of the blank prevent the formation of oxidative DNA damage induced by $\mathrm{H}_{2} \mathrm{O}_{2}$ in vitro. In view of the fact that fermented aleurone had no additional effect compared with the faeces control, other so far unidentified metabolites resulting from the faecal inoculum might be responsible for the anti-genotoxic effect. Other studies that have compared the anti-genotoxic efficacy of fermentation samples also detected effects of the fs of the blank ${ }^{(5)}$. The mechanism by which the fermented samples reduce $\mathrm{H}_{2} \mathrm{O}_{2}$-induced DNA damage in colon cells is still not clear. In the present study the reduced DNA damage could be possibly caused by the increased mRNA expression and enzyme activity of CAT and GST even though these parameters were not influenced by the faeces control. However, this anti-genotoxicity possibly arises from direct antioxidative activities and/or modification of DNA repair mechanisms ${ }^{(11,56)}$.

In conclusion, the present study demonstrates that fermentation products of wheat aleurone can increase mRNA expression of genes involved in detoxifying processes. This induction resulted in an enhanced activity of selected enzymes, namely GST and CAT. These enzymes play an important role in the protection against oxidative DNA damage. However, if HT29 cells are regarded as a model for colon cells in general, our investigations highlighted mechanisms which support an enhanced potential of detoxification of cancer risk factors that may influence the initiation and promotion of cancer. More importantly, we showed evidence that protection can also be increased in normal colon epithelial stripes from human surgeries which emphasises a possible role of wheat aleurone in cancer prevention. Since wheat aleurone showed similar biological effects in both human colon cells we may assume that the same underlying mechanisms probably prevail.

Hence, the modulation of markers of primary chemoprevention indicates that wheat aleurone may possibly have a cancer-preventive potential. Nevertheless, further studies using isolated human primary cells as well as animal studies and/or human intervention trials are required to define a role in primary cancer prevention by fermentation products of wheat aleurone under in vivo conditions.

\section{Acknowledgements}

For funding we would like to thank the Federal Ministry of Education and Research, Germany (BMBF 0313829A).

We thank N. Wachter (Kampffmeyer Food Innovation GmbH, Hamburg, Germany) for providing the wheat aleurone and W. von Reding (Bühler AG, Uzwil, Switzerland) for preparation of the aleurone fraction from wholemeal wheat flour. We are grateful to $H$. Mothes (Hospital Friedrich-Schiller-University Jena, Germany) for providing the colon surgery samples. Furthermore, we thank all donors of colon tissue for giving their informed consent and supporting our studies. Finally, we gratefully acknowledge the excellent assistance by Ms Esther Woschee and Ms Anika Schettler.

K. S., A. B., D. S. and M. G designed the research and wrote the paper. K. S. and A. B. performed the in vitro 
fermentation and the experiments on gene expression. K. S. measured the enzyme activities and anti-genotoxicity.

The authors have no conflicts of interest.

\section{References}

1. Amrein TM, Gränicher P, Arrigoni E, et al. (2003) In vitro digestibility and colonic fermentability of aleurone isolated from wheat bran. Lebenssm WissTechnol 36, 451-460.

2. Hughes SA, Shewry PR, Li L, et al. (2007) In vitro fermentation by human fecal microflora of wheat arabinoxylans. J Agric Food Chem 55, 4589-4595.

3. Scharlau D, Borowicki A, Habermann N, et al. (2009) Mechanisms of primary cancer prevention by butyrate and other products formed during gut flora-mediated fermentation of dietary fibre. Mutat Res 682, 39-53.

4. Abrahamse SL, Pool-Zobel BL \& Rechkemmer G (1999) Potential of short chain fatty acids to modulate the induction of DNA damage and changes in the intracellular calcium concentration by oxidative stress in isolated rat distal colon cells. Carcinogenesis 20, 629-634.

5. Glei M, Hofmann T, Kuster K, et al. (2006) Both wheat (Triticum aestivum) bran arabinoxylans and gut flora-mediated fermentation products protect human colon cells from genotoxic activities of 4-hydroxynonenal and hydrogen peroxide. J Agric Food Chem 54, 2088-2095.

6. Beyer-Sehlmeyer G, Glei M, Hartmann E, et al. (2003) Butyrate is only one of several growth inhibitors produced during gut flora-mediated fermentation of dietary fibre sources. $\mathrm{Br} \mathrm{J} \mathrm{Nutr}$ 90, 1057-1070.

7. Das D, Arber N \& Jankowski JA (2007) Chemoprevention of colorectal cancer. Digestion 76, 51-67.

8. Wattenberg LW (1993) Prevention-therapy-basic science and the resolution of the cancer problem. Cancer Res 53, 5890-5896.

9. Deshpande SS \& Irani K (2002) Oxidant signalling in carcinogenesis: a commentary. Hum Exp Toxicol 21, 63-64.

10. Hamer HM, Jonkers DM, Bast A, et al. (2009) Butyrate modulates oxidative stress in the colonic mucosa of healthy humans. Clin Nutr 28, 88-93.

11. Rosignoli P, Fabiani R, De Bartolomeo A, et al. (2001) Protective activity of butyrate on hydrogen peroxide-induced DNA damage in isolated human colonocytes and HT29 tumour cells. Carcinogenesis 22, 1675-1680.

12. Matés JM, Pérez-Gómez C \& Núñez de Castro I (1999) Antioxidant enzymes and human diseases. Clin Biochem 32, $595-603$

13. Gupta A, Butts B, Kwei KA, et al. (2001) Attenuation of catalase activity in the malignant phenotype plays a functional role in an in vitro model for tumor progression. Cancer Lett 173, 115-125.

14. Klaunig JE \& Kamendulis LM (2004) The role of oxidative stress in carcinogenesis. Annu Rev Pharmacol Toxicol 44, 239-267.

15. Sauer J, Richter KK \& Pool-Zobel BL (2007) Physiological concentrations of butyrate favorably modulate genes of oxidative and metabolic stress in primary human colon cells. J Nutr Biochem 18, 736-745.

16. Pool-Zobel BL, Abrahamse SL, Collins AR, et al. (1999) Analysis of DNA strand breaks, oxidized bases, and glutathione $S$-transferase P1 in human colon cells from biopsies. Cancer Epidemiol Biomarkers Prev 8, 609-614.

17. Cotterchio M, Boucher BA, Manno M, et al. (2008) Red meat intake, doneness, polymorphisms in genes that encode carcinogen-metabolizing enzymes, and colorectal cancer risk. Cancer Epidemiol Biomarkers Prev 17, 3098-3107.

18. Hoensch H, Peters WH, Roelofs HM, et al. (2006) Expression of the glutathione enzyme system of human colon mucosa by localisation, gender and age. Curr Med Res Opin 22, $1075-1083$.

19. Bowman KG \& Bertozzi CR (1999) Carbohydrate sulfotransferases: mediators of extracellular communication. Chem Biol 6, R9-R22.

20. Borowicki A, Stein K, Scharlau D, et al. (2010) Fermented wheat aleurone inhibits growth and induces apoptosis in human HT29 colon adenocarcinoma cells. Br J Nutr 103, 360-369.

21. Bohm A, Bogoni C \& Behrens R, et al. (2002) Method for the extraction of aleurone from bran. International patent WO 02/15711 A2. Uzwil, Switzerland: Bühler AG.

22. Aura AM, Härkönen H, Fabritius M, et al. (1999) Development of an in vitro enzymatic digestion method for removal of starch and protein and assessment of its performance using rye and wheat breads. J Cereal Sci 29, 139-152.

23. Glei M, Kirmse A, Habermann N, et al. (2006) Bread enriched with green coffee extract has chemoprotective and antigenotoxic activities in human cells. Nutr Cancer 56, 182-192.

24. Schaeferhenrich A, Sendt W, Scheele J, et al. (2003) Putative colon cancer risk factors damage global DNA and TP53 in primary human colon cells isolated from surgical samples. Food Chem Toxicol 41, 655-664.

25. Rogler G, Daig R, Aschenbrenner E, et al. (1998) Establishment of long-term primary cultures of human small and large intestinal epithelial cells. Lab Invest 78, 889-890.

26. Veeriah S, Miene C, Habermann N, et al. (2008) Apple polyphenols modulate expression of selected genes related to toxicological defence and stress response in human colon adenoma cells. Int $J$ Cancer 122, 2647-2655.

27. Pfaffl MW, Horgan GW \& Dempfle L (2002) Relative expression software tool (REST) for group-wise comparison and statistical analysis of relative expression results in realtime PCR. Nucleic Acids Res 30, e36.

28. Aebi H (1984) Catalase in vitro. Methods Enzymol 105, $121-126$.

29. Habig WH, Pabst MJ \& Jakoby WB (1974) Glutathione $S$-transferases: the first enzymatic step in mercapturic acid formation. J Biol Chem 249, 7130-7139.

30. Bradford MM (1976) A rapid and sensitive method for the quantitation of microgram quantities of protein utilizing the principle of protein-dye binding. Anal Biochem 72, 248-254.

31. Glei M, Matuschek M, Steiner C, et al. (2003) Initial in vitro toxicity testing of functional foods rich in catechins and anthocyanins in human cells. Toxicol In Vitro 17, 723-729.

32. Singh NP, McCoy MT, Tice RR, et al. (1988) A simple technique for quantitation of low levels of DNA damage in individual cells. Exp Cell Res 175, 184-191.

33. World Cancer Research Fund \& American Institute for Cancer Research (2007) Food, Nutrition, Physical Activity and the Prevention of Cancer: a Global Perspective. Washington, DC: AIRC.

34. Bingham SA, Day NE, Luben R, et al. (2003) Dietary fibre in food and protection against colorectal cancer in the European Prospective Investigation into Cancer and Nutrition (EPIC): an observational study. Lancet 361, 1496-1501.

35. Schatzkin A, Freedman LS, Lanza E, et al. (1995) Diet and colorectal cancer: still an open question. J Natl Cancer Inst 87, 1733-1735.

36. Schatzkin A, Lanza E, Corle D, et al. (2000) Lack of effect of a low-fat, high-fiber diet on the recurrence of colorectal adenomas. Polyp Prevention Trial Study Group. N Engl J Med 342, 1149-1155. 
37. Clapper ML \& Szarka CE (1998) Glutathione $S$-transferases biomarkers of cancer risk and chemopreventive response. Chem Biol Interact 111-112, 377-388.

38. Mattes WB, Daniels KK, Summan M, et al. (2006) Tissue and species distribution of the glutathione pathway transcriptome. Xenobiotica 36, 1081-1121.

39. Matés JM (2000) Effects of antioxidant enzymes in the molecular control of reactive oxygen species toxicology. Toxicology 153, 83-104.

40. Pool-Zobel B, Veeriah S \& Bohmer FD (2005) Modulation of xenobiotic metabolising enzymes by anticarcinogens - focus on glutathione $S$-transferases and their role as targets of dietary chemoprevention in colorectal carcinogenesis. Mutat Res 591, 74-92.

41. Kwak MK, Wakabayashi N \& Kensler TW (2004) Chemoprevention through the Keap1-Nrf2 signaling pathway by phase 2 enzyme inducers. Mutat Res 555, 133-148.

42. Harvey CJ, Thimmulappa RK, Singh A, et al. (2009) Nrf2regulated glutathione recycling independent of biosynthesis is critical for cell survival during oxidative stress. Free Radic Biol Med 46, 443-453.

43. Chan K, Han XD \& Kan YW (2001) An important function of Nrf2 in combating oxidative stress: detoxification of acetaminophen. Proc Natl Acad Sci U S A 98, 4611-4616.

44. Itoh K, Chiba T, Takahashi S, et al. (1997) An Nrf2/small Maf heterodimer mediates the induction of phase II detoxifying enzyme genes through antioxidant response elements. Biochem Biophys Res Commun 236, 313-322.

45. Roberfroid MB (2005) Introducing inulin-type fructans. $\mathrm{Br}$ J Nutr 93, Suppl. 1, S13-S25.

46. Treptow-van Lishaut S, Rechkemmer G, Rowland I, et al. (1999) The carbohydrate crystalean and colonic microflora modulate expression of glutathione $S$-transferase subunits in colon of rats. Eur J Nutr 38, 76-83.

47. Pool-Zobel BL, Selvaraju V, Sauer J, et al. (2005) Butyrate may enhance toxicological defence in primary, adenoma and tumor human colon cells by favourably modulating expression of glutathione $S$-transferases genes, an approach in nutrigenomics. Carcinogenesis 26, 1064-1076.

48. Kautenburger T, Beyer-Sehlmeyer G, Festag G, et al. (2005) The gut fermentation product butyrate, a chemopreventive agent, suppresses glutathione $S$-transferase theta (hGSTT1) and cell growth more in human colon adenoma (LT97) than tumor (HT29) cells. J Cancer Res Clin Oncol 131, $692-700$.

49. Ebert MN, Beyer-Sehlmeyer G, Liegibel UM, et al. (2001) Butyrate induces glutathione $S$-transferase in human colon cells and protects from genetic damage by 4-hydroxy-2-nonenal. Nutr Cancer 41, 156-164.

50. Fenton JI \& Hord NG (2006) Stage matters: choosing relevant model systems to address hypotheses in diet and cancer chemoprevention research. Carcinogenesis 27, 893-902.

51. Saini SP, Sonoda J, Xu L, et al. (2004) A novel constitutive androstane receptor-mediated and CYP3A-independent pathway of bile acid detoxification. Mol Pharmacol 65, 292-300.

52. Ebert MN, Klinder A, Peters WH, et al. (2003) Expression of glutathione $S$-transferases (GSTs) in human colon cells and inducibility of GSTM2 by butyrate. Carcinogenesis 24, 1637-1644.

53. Ferguson LR \& Harris PJ (2003) The dietary fibre debate: more food for thought. Lancet 361, 1487-1488.

54. Yano S \& Tierney DF (1989) Butyrate increases catalase activity and protects rat pulmonary artery smooth muscle cells against hyperoxia. Biochem Biophys Res Commun 164, $1143-1148$.

55. Clifford MN (2000) Chlorogenic acids and other cinnamates nature, occurrence, dietary burden, absorption and metabolism. J Sci Food Agric 80, 1033-1043.

56. Sandström BE \& Marklund SL (1990) Effects of variation in glutathione peroxidase activity on DNA damage and cell survival in human cells exposed to hydrogen peroxide and $t$-butyl hydroperoxide. Biochem J 271, 17-23. 